\title{
Technology and Regional Social Structures: Evaluation of Remote Sign Language Interpretation in Finland
}

\author{
Jouko Kokko, Erkki Kemppainen, and Aulikki Rautavaara \\ Stakes, PBox 220, 00531 Helsinki, Finland \\ Jouko.kokko@stakes.fi
}

\begin{abstract}
During the years 2001-2004 STAKES implemented a national development project VETURI - networking interpreter services -. Its objective was to improve the preconditions for the availability and quality of interpreter services. The starting point for this development work was to provide a service with a sufficiently large population base, in the form of regionally co-ordinated network co-operation of a variety of stakeholders. A part of the service in the project was given as remote videophone service. Remote interpreting made an interpreter's work easier because she did not need to travel and was able to work from a familiar work location. New ways to produce services enabled the growth of remote interpretation service. Larger population base and service resources made it possible to bring service also there where it has not been earlier.
\end{abstract}

Keywords: Disability, Interpretation service, hard of hearing people, ICT.

\section{Introduction}

The aims of Finland's disability policy are equitable treatment and support for life management, working capacity, functional capacity and independence. Measures include services, rehabilitation and removal of barriers. The aim is for all general services to be appropriate and sufficient for all citizens; special services such as housing, assistive devices, transportation and interpreter services are never a first resort.

A personal service plan is drawn up for each disabled person to clarify the services and support he or she requires. Officials of the municipality together with the client and his or her carer or relatives prepare the plan. The service plan is designed to improve the clients' autonomy and their possibilities to influence their situation. A counsellor, who is tasked to accommodate the various services together and call meetings of other relevant officials, checks the plan within specified timeframes [6].

\subsection{Interpretation Services}

People whose hearing is severely impaired, who are deaf and blind or who suffer speech disabilities are entitled to free interpretation services arranged by their municipality. Interpretation services are provided in sigh language or, for example, using new technology [6]. 


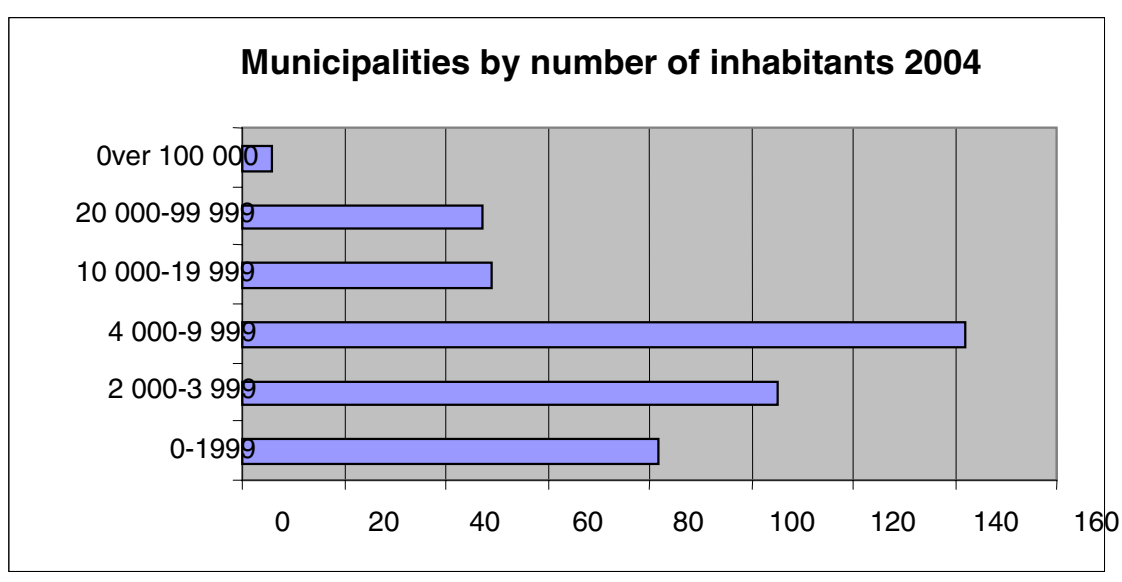

Fig. 1. Municipalities by number of inhabitants 2004 in Finland

The responsibility for the arranging of interpreter services lies with municipalities, which must arrange a minimum of 120 hours of interpreting per year for deaf sign language users (1.1.2007 180 hours). There were 432 municipalities year 2005 (417 year 2007) in Finland. Most of municipalities are rather small, the number of inhabitants is under 10000 [1]. The population is concentrated in South-Western Finland and eastern and northern parts of Finland are sparsely populated, 2-7 persons per $\mathrm{km}^{2}$. Also the distances are rather long. About $30 \%$ of all municipalities did not give interpretation services in 2005 [5]. This means that usually small municipalities don't have the skill.

Table 1. Interpreter service recipients during the year [5]

\begin{tabular}{lccc}
\hline 1994 & 2000 & $\mathbf{2 0 0 3}$ & $\mathbf{2 0 0 4}$ \\
\hline 2716 & 3137 & 3351 & 3398 \\
& & & \\
$\%$ of the population & & \\
0,05 & 0,06 & 0,06 & 0,06 \\
\hline
\end{tabular}

\section{Development Project}

During the years 2001-2004 National Research and Development Centre for Welfare and Health (STAKES) implemented a development project VETURI - networking interpreter servioces - commissioned by the Finnish Ministry of Social Affairs and Health. Its objective was to improve the preconditions for the availability and quality of interpreter services set by the Act on Services and Assistance for the Disabled, throughout Finland. The starting point for this development work was to provide a service with a sufficiently large population base, in the form of regionally coordinated network co-operation of a variety of stakeholders [4]. 
A part of the service in the project was given as remote videophone service. In the project videophone consisted of pc-computer, video camera, ISDN or IP connection and videophone software. In the beginning there were more ISDN connections but later most of them were changed to IP connections. The project did not provide any new equipment but both the customers and services centres used their own equipment.

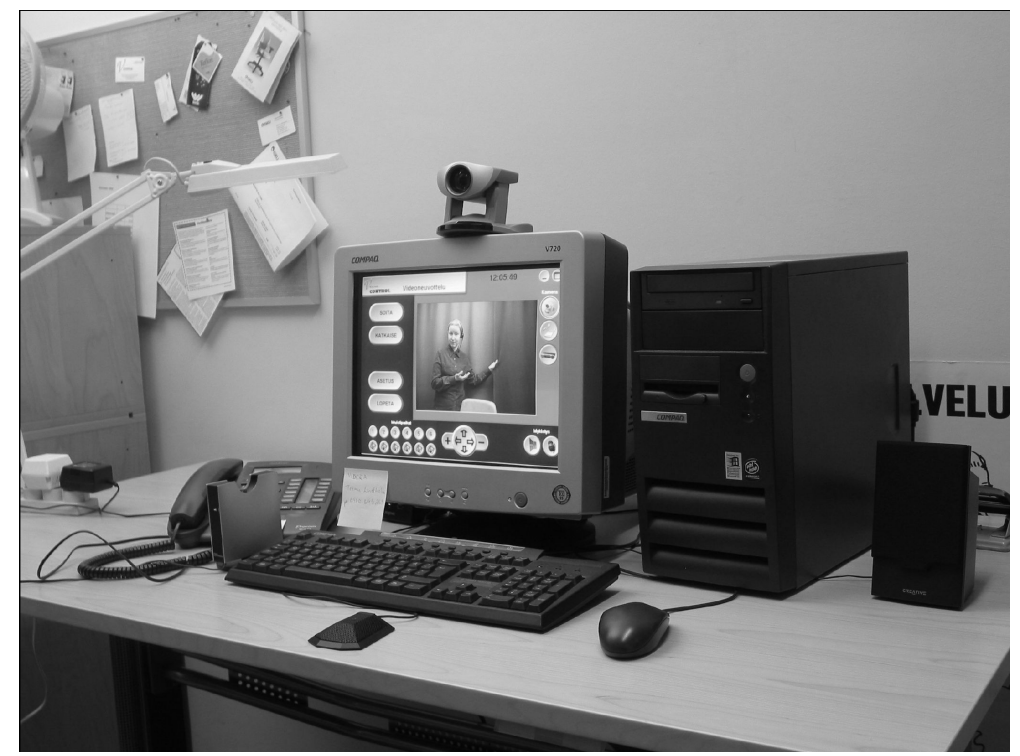

Fig. 2. Videophone workstation [3]

Interpreter was using one workstation and user contacted her/him from another workstation. Usually hard of hearing or death person uses her/his own workstation to order interpretation service. Workstation can be also in some other place for instance in social office. Then often social worker takes connection to interpreter and dialog between hard of hearing customer and social worker begins via interpreter. This is called a two point service.

A multipoint service started during the project and this is a goal. There all three persons can be in the different places. The service centre takes all the calls. The interpretation service is decentralized to different interpretation organisations and locations in the country. A duty list is prepared for interpreters. The caller can see the list of available interpreters and can connect to the first in the list or someone familiar. In some cases the server in the service centre has software for invoicing. It has records of clients, interpreters and the municipalities which pay the service. According to time used and other circumstances program calculates the bill and sends it to responsible municipality.

Requirements to equipments and software are: basic pc or laptop computer, video camera, ISDN $(2 \times 3 \times 124 \mathrm{~Kb})$ or Internet connection $(2 \times 384 \mathrm{~Kb}$, recommended 1 $\mathrm{Mb}$ ), videophone software with voice communication facility (recommended also text) (frame rate minimum $18 \mathrm{p} / \mathrm{sec}$, recommended $25 \mathrm{p} / \mathrm{sec}$ ). 


\section{Multipoint service}

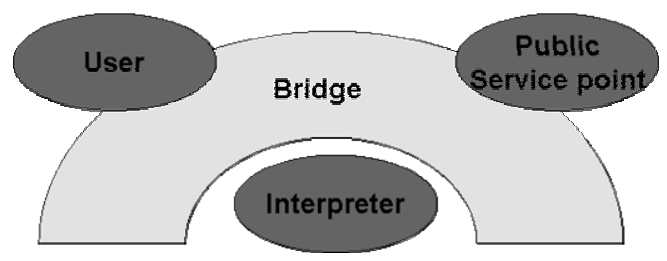

Fig. 3. Multipoint remote interpretation service

There have been technical problems especially with firewalls. Some programs change all the time ports for communication. This means that several ports ought to be open through the firewall during connection. Certain software requires fast IP address, but home users have it rarely. Compatible problems occur also quite often. But all the same technology has been working pretty well. To get a reasonable video picture a user needs $384 \mathrm{~Kb}$ connections to both directions. In practice the speed ought to be bigger rather $512 \mathrm{~Kb}$ to both directions. Selected software seems to work well also in wireless (wlan) environments [2].

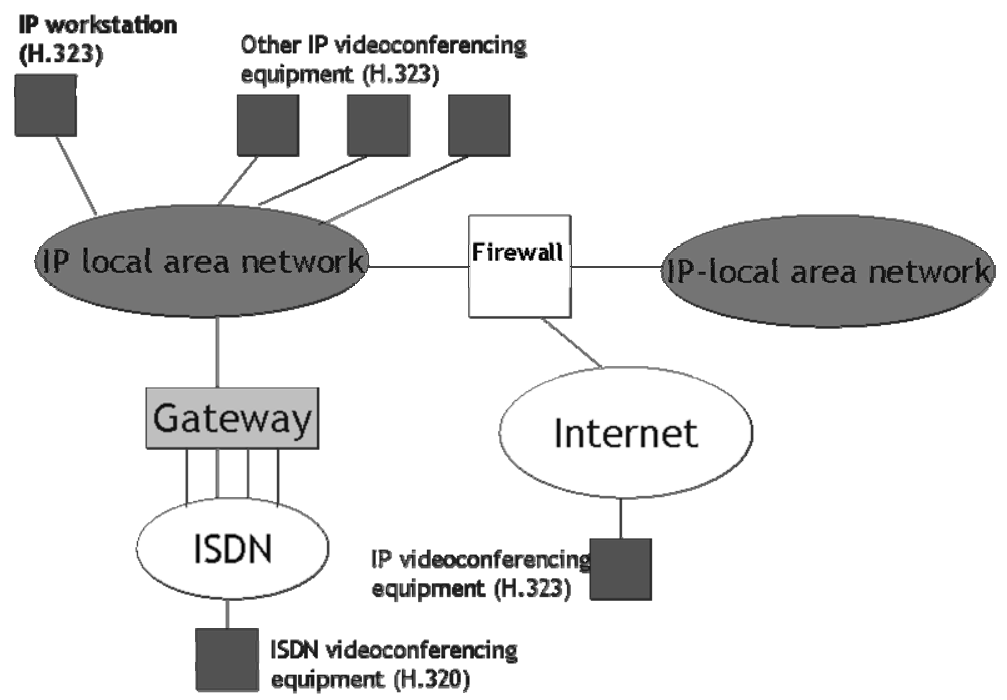

Fig. 4. Remote interpretation network [2] 


\section{Evaluation}

The goal of the evaluation was to define the efficiency of the network project and its impacts on the regional development work of the interpreter service. The main source of information was the response data obtained from a thematic survey addressed to the regional presidents of the VETURI groups. Additional source material included project feedback from 2005, obtained from STAKES Information Services, as well as documentation and interim reports of the project. This material was related to the organisation and co-ordination of the project and contained descriptions and analyses of information systematically collected during the project from the presidents of the regional groups.

According to the impact evaluation, VETURI project generated the expected benefits. Positive outcomes include strengthening regional thinking with regard to organising and providing interpreter services. The utilisation of regional resources and their channelling in support of municipalities has been improved. The project set significant regional change processes in motion. New service structures, working and operating methods were developed out in different parts of Finland. Some of these are now established as permanent activities in the service structure, and some results will be further developed in new development projects. Concrete decisions have been made and confirmed by agreements, on the regionally organised provision and sourcing of interpreter services, and more decisions are to be expected. Rising trends in demand for, and the supply of, interpreter services were confirmed in all project areas that answered the survey. Hidden demand in the regions is in the process of being identified. None of the groups using interpreter services faced a decrease in the provision of these services. The deployment of new technology showed progress in the regions, but differences existed in the speed of such development.

The preconditions for the availability and quality of interpreter services appear to be improving in different parts of Finland, in the intended direction. An interpreter service cannot be replaced with other services. Users of interpreter services need them during their entire lives, or the rest of their lives, after the initial need has arisen. An interpreter service is essential to the person needing it, in terms of the realisation of equality and social inclusion. There are ways and various alternatives for improving the irregular service situation for different regions and disability groups. In VETURI project, progress was made in finding solutions for many essential issues concerning regional co-operation. In the future, interpreter services will enjoy the support of expert resources organised into regional networks, newly launched projects and highlevel interpreter training.

Despite this progress, mutual co-operation between municipalities in organising the services seems very challenging. It will also be necessary to continue finding solutions to issues concerning the division of work between, and specialisations of, regional providers. Much remains to be done regarding the use of information and communication technologies and their integration into service provision, as well as ensuring professional know-how and communication on the municipal level. The need for information within various disabled groups remains extensive.

The development of regional networks for one service type designed for the disabled has opened up horizons for the regional development of other services. In the 
future, a possible and natural step will be to develop services for the disabled further, according to the customers' individual needs. This can be achieved by developing a particular service or by integrating services into a larger entity, necessitating agreement on how to ensure a sufficiently strong structural and economic base for them [4].

Remote interpreting made an interpreter's work easier because she did not need to travel and was able to work from a familiar work location. On the other hand, remote interpreting posed new challenges to an interpreter's work, because interpreting assignments came unexpectedly with a variety of topics and without a chance to prepare in advance. The use of technology also contributed to the challenging nature of the work [3].

New forms to produce services enabled the growth of remote interpretation service. Bigger population base and service resources made it possible to bring service also there where it has not been earlier. In some areas like in Northern-Carelia which is rather sparsely populated the amount interpretation service given as remote service raised to $12 \%$. Introduce of new technology can help in the strained economic situation of municipalities [4].

\section{References}

1. Facts about Social Welfare and Healthcare in Finland 2006. Stakes, Helsinki (2006)

2. Hämäläinen, Pentti, Tainio, Marika: Etätulkkaus ja sen tekniikka. Kuurojen multimodaaliset tulkkipalvelut eli Kumu projeketin 2005-2006 loppuraportti. English Abstract. The Multimodal Interpreting Services for Deaf. p.62 Kuurojen liitto, Helsinki (2006). ISSN 1457-1099

3. Marjanen, Kati, Tainio, Marika: Esteetön etätulkkaus. English summary. The Accessible Remote Interpreting Project. p. 50 Kuurojen liitto, Helsinki (2004)

4. Rautavaara, Aulikki, Kokko, Jouko: Networking Interpreter Services for People with Hearing or Speech Impairment. Assessment of the Efficiency and Impacts of Regional Cooperation. p. 89 (Reports of the Ministry of Social Affairs and Health, ISSN 1236-2115; 2006:51)

5. Web-based database service by Stakes http://www.stakes.fi/EN/tilastot/sotkanet/sotkanet. htm

6. Ministry of Social Welfare and Healthcare http://www.stm.fi/Resource.phx/eng/subjt/ socwe/disab/index.htx 